\title{
Study of Self-reversal of TRM in Some Submarine Basalts
}

\author{
Mituko OzIMA \\ Geophysical Institute, University of Tokyo \\ and \\ E.E. LARSON \\ Department of Geology, University of Colorado
}

(Received May 22; revised August 2, 1968)

\begin{abstract}
Three of eight submarine basalts from various localities of the Pacific show self-reversal of TRM when they are heated in air at about $300^{\circ} \mathrm{C}$ and cooled to room temperature in the geomagnetic field. As the sample is heated to $300^{\circ} \mathrm{C}$, the original ferrimagnetic component with a Curie temperature of $250^{\circ} \mathrm{C}$ is gradually transformed to another component with a Curie temperature of $300^{\circ} \mathrm{C}$ and there exist momentarily two magnetic components. Magnetic interaction between these two components seems to be responsible for selfreversal. The fact that TRM produced in an external field of $2600 \mathrm{O} e$ reverses at low temperatures indicates that the self-reversal phenomenon is caused by an exchange interaction.
\end{abstract}

\section{Introduction}

Since the discovery of self-reversal in the Haruna dacite (Nagata et al, 1951), several cases involving synthetic compounds and rock-forming minerals have been reported (See Table I for a summary). Reports of self-reversal of remanent magnetization in basalts, however, are extremely rare (Meitzner, 1963; Havard and Lewis, 1965; Schult, 1965).

During the study of the magnetic properties of eight submarine basalt samples from various parts of the Pacific Ocean basin, three were found to show a self-reversal of TRM at room temperature after heating over a restricted temperature range. These results are certainly interesting at a time when so much attention is being given to the interpretation of the magnetic-anomaly lineation patterns in the ocean basins. The common occurrence of self-reversal in our small statistical sample would imply that a large proportion of oceanic basaltic rocks should be expected to behave similarly.

In this paper are reported some experimental results of studies carried out on the three basalt samples which underwent self-reversal of TRM. A more detailed description, including the location of the dredge sites and some magnetic properties of each sample, is given in an article by Ozima et al (1968).

\section{Experimental Results}

\section{(1) Magnetic Properties}

\section{General Statement}

In the course of study of the magnetic properties of the eight oceanic basalt samples a 
Table I

\begin{tabular}{|c|c|c|c|}
\hline Age & Author & Material & Mechanism \\
\hline 1888 & Nagaoka & nickel & $\begin{array}{l}\text { combined effects of torsion } \\
\text { and stress }\end{array}$ \\
\hline 1912 & Smith and Guild & annealed steel & demagnetizing field ${ }^{(2)}$ \\
\hline 1951 & $\begin{array}{l}\text { Nagata, Akimoto and } \\
\text { Uyeda }\end{array}$ & $\begin{array}{l}\text { Il-Ht series }{ }^{(3)} \\
\left(x \mathrm{FeTiO}_{3} \cdot(1-x) \mathrm{Fe}_{2} \mathrm{O}_{3}\right) \\
x \approx 0.5\end{array}$ & exchange interaction ${ }^{(3)(4)}$ \\
\hline 1953 & Gorter and Schulkes & $\mathrm{Li}$-Cr-ferrite & reversal of $J_{s}$ \\
\hline 1958 & Uyeda & Li-Cr-ferrite & reversal of $J_{s}$ \\
\hline 1960 & Akimoto and Yama-ai & $\begin{array}{l}\text { Il-Ht series } \\
x \approx 0.07-0.44\end{array}$ & $?$ \\
\hline 1961 & Carmichael & $\begin{array}{l}\text { Il-Ht series } \\
x \approx 0.1\end{array}$ & electron transfer \\
\hline 1961 & Gusev $^{(6)}$ & (ultra-basic rock) & $?$ \\
\hline 1962 & Everitt & pyrrhotite & magnetostatic interaction \\
\hline 1962 & Sakamoto & $\mathrm{Co}_{2} \mathrm{TiO}_{4}$ & reversal of $J_{s}$ \\
\hline 1963 & Ozima & $\mathrm{Co}_{\delta} \mathrm{Fe}_{3-\delta} \mathrm{O}_{4}(\delta=0.02)$ & magnetostatic interaction \\
\hline 1963 & Yama-ai, Ozima and Nagata & $\mathrm{Fe}_{3} \mathrm{O}_{4}$ & magnetostatic interaction \\
\hline 1963 & Meitzner & (basalt) & oxidation process \\
\hline 1964 & Bhimasankaram & pyrrhotite & magnetostatic interaction \\
\hline 1964 & Ozima, Ozima and Akimoto & cobalt & magnetostatic interaction \\
\hline 1964 & $\begin{array}{l}\text { Vlasov, Zvegintev and } \\
\text { Pavlov }\end{array}$ & $\left.\begin{array}{l}\text { Il-Ht series } \\
\mathrm{Li}-\mathrm{Cr} \text {-ferrite }\end{array}\right\}$ & \\
\hline 1965 & Havard and Lewis & $\begin{array}{l}\text { (basalt) and } \\
\text { titanomagnetite }\end{array}$ & magnetostatic interaction \\
\hline 1965 & Schult & (basalt) & reversal of $J_{s}$ \\
\hline 1967 & Kobayashi and Fuller & nickel & \\
\hline 1967 & Ozima and Ozima & (basalt) & exchange interaction \\
\hline
\end{tabular}

(1) Carmichael and Fuller, 1967.

(2) Smith, Dee and Mayneord, 1924.

(3) Uyeda, 1958.

(4) Ishikawa and Syono, 1962.

(5) The same result have been reported by Uyeda (1958).

(6) Kalashnikov et al, 1961.

determination of paleomagnetic intensity (using Thellier's stepwise-heating method) was attempted. The shape of the samples is a cylinder one inch in diameter and one inch in height. Three (WPDR-2, WPDR-8, EPDR-2) of the eight samples produced an anomalous curve of TRM: they showed self-reversal when cooled to room temperature in the geomagnetic field after being heated in air to certain temperatures $\left(T=300^{\circ} \mathrm{C}\right)(\mathrm{Ozima}$ et al, 1968). Fig. 1-a, 1-b and 1-c show these results. The solid line indicates a thermal-decay mode

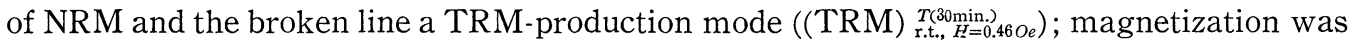
measured at room temperature. Here, $T(30 \mathrm{~min}$.) means that the sample was heated at $T$ for 30 minutes. These results are very similar to those of Havard and Lewis (1965) who studied some basalt flows from India. To try to understand the mechanism of the reverse TRMs, all three samples were carefully studied and WPDR-2 was examined in detail. 


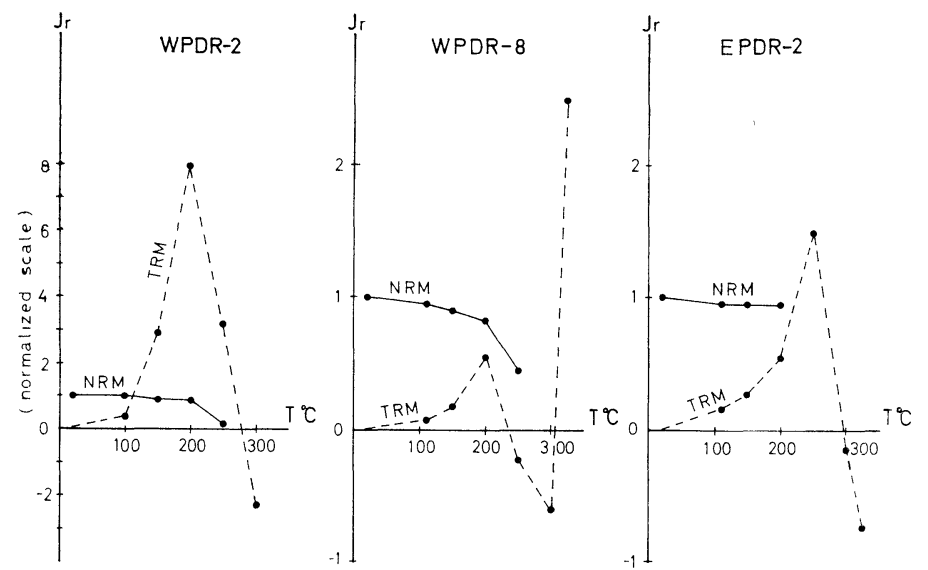

Fig. 1 Thermal-demagnetization of NRM and production of TRM by Thellier's method for (1-a) WPDR-2, (1-b) WPDR-8, and (1-c) EPDR-2 samples. Samples were heated in air at a temperature (as shown on the abscissa) for 30 minutes and cooled to room temperature in the geomagnetic field. Remanent magnetizations were measured at room temperature.

Results from WPDR-2

Fig. 2 shows the TRM-production of

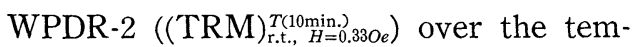
perature range from room temperature to $600^{\circ} \mathrm{C}$. The ordinate represents an intensity of thermoremanent magnetization produced by cooling the sample in air from various temperatures (as shown on the abscissa) to room temperature in the horizontal component of the geomagnetic field. For this experiment, the sample was tabular $(1 \mathrm{~cm} \times 1 \mathrm{~cm} \times 0.5 \mathrm{~cm})$. As shown in the figure, the intensity of TRM is greatly dependent on the temperature of heattreatment. Thermoremanent magnetization produced below $300^{\circ} \mathrm{C}$ has a direction parallel to the ambient field, whereas that produced between $300^{\circ} \mathrm{C}$ and $330^{\circ} \mathrm{C}$ has a direction antiparallel to the field. When the sample is cooled from above $330^{\circ} \mathrm{C}$, the thermoremanent magnetization again becomes parallel to the ambient field.

Two sharp rdents in the TRM curve are observed, one at about $300^{\circ} \mathrm{C}$ and the

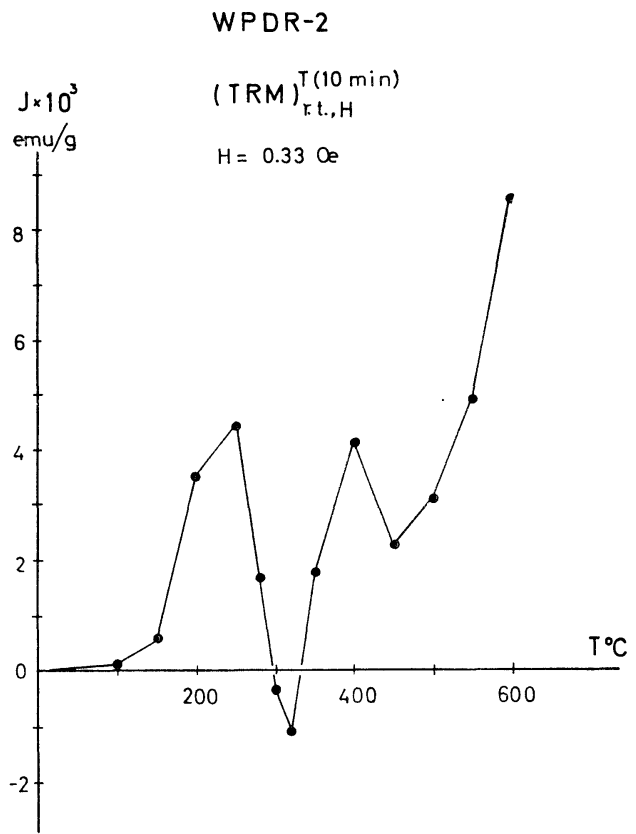

Fig. 2 Production of thermoremanent magnetization of WPDR-2. When the sample is heated at $300-330^{\circ} \mathrm{C}$ in air for 10 minutes and cooled to room temperature in the geomagnetic field, the thermoremanent magnetization is reversed. 


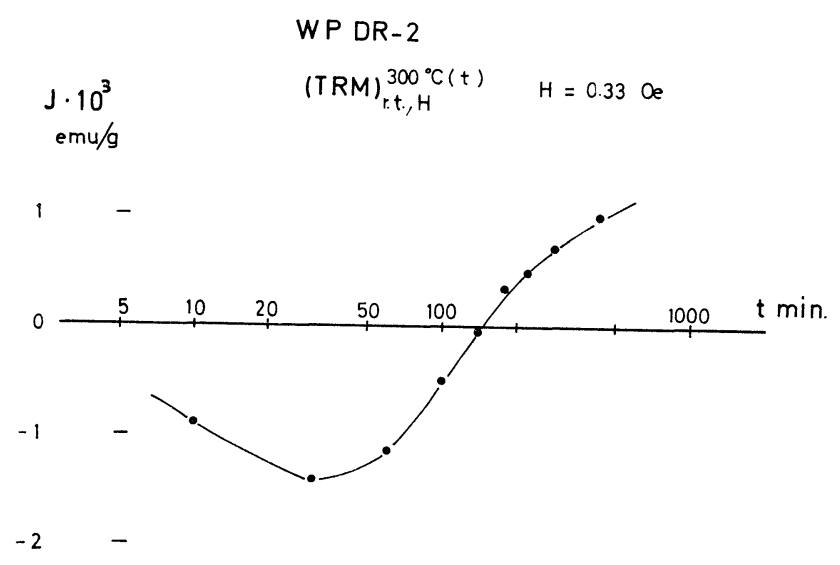

Fig. 3 Change in intensity of TRM with duration the sample is kept at $300^{\circ} \mathrm{C}$.

other at $500^{\circ} \mathrm{C}$. They seem to indicate that some change in magnetic properties took place at these temperatures during the heating to $600^{\circ} \mathrm{C}$. The second change is associated with a large increase in the intensity of magnetization and Curie temperature. A description of this behaviour is given in the paper by Ozima et al (1968).

The occurrence of self-reversal is sensitive to the duration of heat-treatment. In Fig. 3, the TRM intensities are plotted against the time each sample was kept at $300^{\circ} \mathrm{C}$ in air in the geomagnetic field. As shown, the reversed-TRM intensity increases with an increase in duration of the heat-treatment, up to about 30 minutes. Thereafter, the TRM intensity decreases and when the sample has been heated for 150 minutes or longer it fails to show the self-reversal when cooled to room temperature. However, if cooled below room temperature, these samples again show reversed magnetization. This will be shown later in Fig. 7.

Fig. 4-a shows the thermomagnetic $(J-T)$ curves obtained for sample WPDR-2 in air at $H=4000 O e$. During the initial heating (phase 1) the magnetization decreases almost linearly and finally disappears at $250^{\circ} \mathrm{C}$, indicating that the original sample has predominantly a single magnetic component with a Curie point near $250^{\circ} \mathrm{C}$. When the sample is heated at $400^{\circ} \mathrm{C}$ for several minutes and then cooled (phase 2), the magnetization begins to appear at $300^{\circ} \mathrm{C}$ indicating alteration (probably oxidation and/or unmixing) of some of the original magnetic material to one with an increased Curie point. On further heating at a higher temperature (phase 3 ) the sample alters to a third magnetic component with a Curie point of about $560^{\circ} \mathrm{C}$ (see Figure 4-a). Further recycling (phases 4 and 5) produces no further changes.

Fig. 4-b shows the change of magnetization with temperature in a field of $8000 \mathrm{Oe}$ (at this field strength, the magnetization nearly attains saturation) for the temperature range from $-196^{\circ} \mathrm{C}$ to $300^{\circ} \mathrm{C}$ for three specimens of WPDR-2 prepared under different conditions. The various curves in the figure correspond to 1) the original unheated sample, 2) the sample heated at $300^{\circ} \mathrm{C}$ for 15 minutes which shows self-reversal at room temperature, and 3) the 


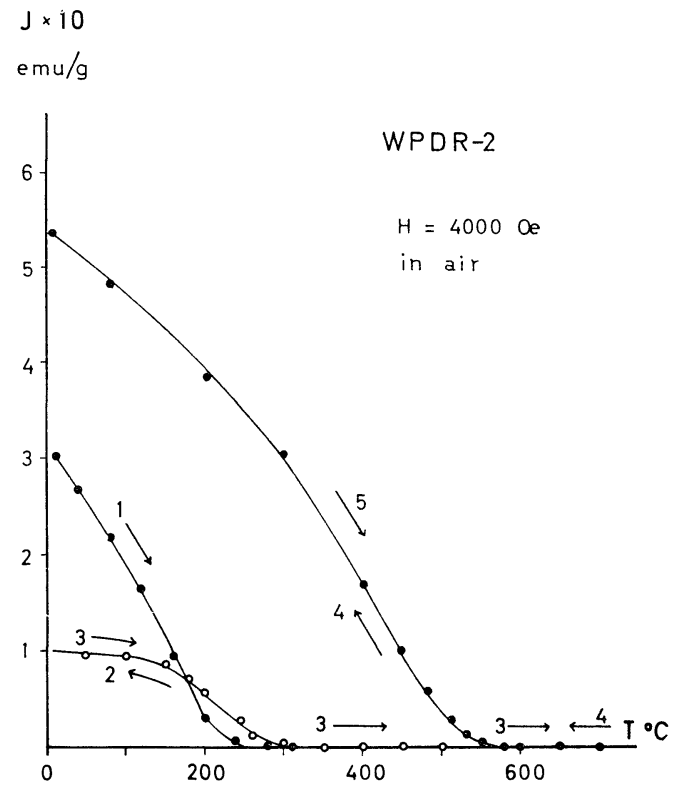

Fig. 4-a Thermomagnetic curves obtained at $H=4000 \mathrm{O} e$ in air. On initial heating, (curve 1), magnetization disappears at $250^{\circ} \mathrm{C}$. When the sample is heated to $400^{\circ} \mathrm{C}$ and then cooled (curve 2), magnetization appears at $300^{\circ} \mathrm{C}$. On subsequent heating (curve 3 ), magnetization changes reversibly on cooling (curve 4) and on heating (curve 5) indicating a single magnetic component of Curie temperature of $560^{\circ} \mathrm{C}$.

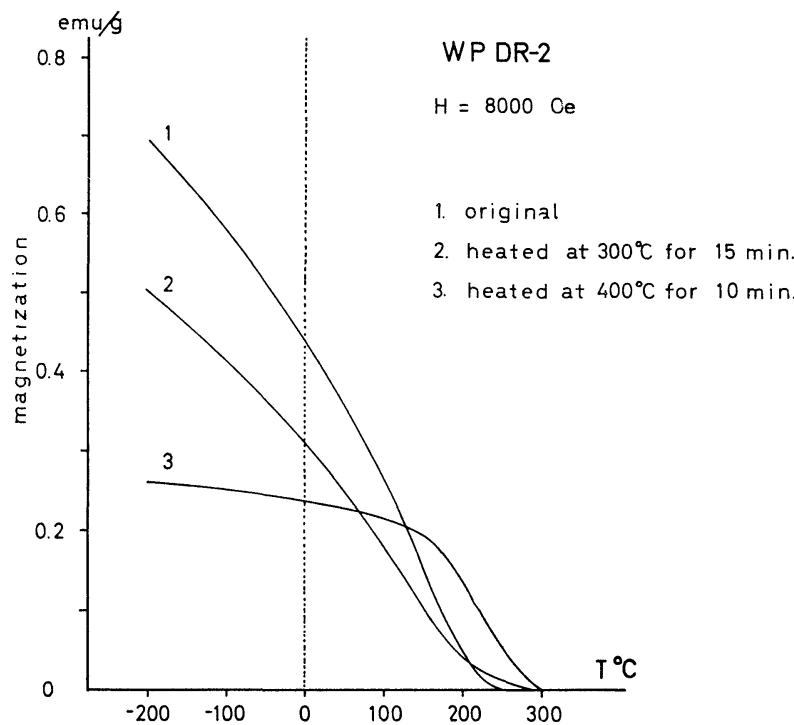

Fig. 4-b Thermomagnetic curves obtained at $H=8000 \mathrm{Oe}$ for the temperature range from $-196^{\circ} \mathrm{C}$ to $300^{\circ} \mathrm{C}$. Three specimens of WPDR-2 were prepared under different conditions. 
sample heated at $400^{\circ} \mathrm{C}$ for 10 minutes which does not show reversed TRM. The general shapes of the curves in Figure 4-b are similar to those in Figure 4-a.

Fig. 5 gives two magnetization curves $(J-H)$ obtained from two specimens of WPDR-2. The one from the unheated specimen indicates that only one magnetic component is present. The one from the specimen heated at $300^{\circ} \mathrm{C}$ for 15 minutes in air (which shows self-reversal) displays obvious kinks in the magnetization curve and this suggests the existence of two magnetic components which resemble a relatively low coercivity, $\mathrm{Fe}_{3} \mathrm{O}_{4}$ like component + a high coercivity, $\alpha \mathrm{Fe}_{2} \mathrm{O}_{3}$ like component.

It is evident from the above two experimental results (Figures 4 and 5) that the selfreversal is predominant in the specimens containing two magnetic components. We may presume that the reversed TRM results from a magnetic interaction between these two components. This view is supported by the fact that when a specimen is heated sufficiently $\left(400^{\circ} \mathrm{C}\right)$ to cause the disappearance of the two phases and production of only one with a higher Curie point, the specimen no longer displays self-reversal. To understand the mechanism responsible for the self-reversal phenomenon, the sample was repeatedly heated to $300^{\circ} \mathrm{C}$ (and was kept at this temperature for 10 minutes on each heating) in a series of fields of increasing magnitude, up to a maximum of $2600 \mathrm{O} e$, and then cooled. The TRM produced, even at $H=2600 O e$, was reversed after cooling. The temperature at which reversal occurred became progressively lower with repeated heatings. As will be explained in section 3 , this

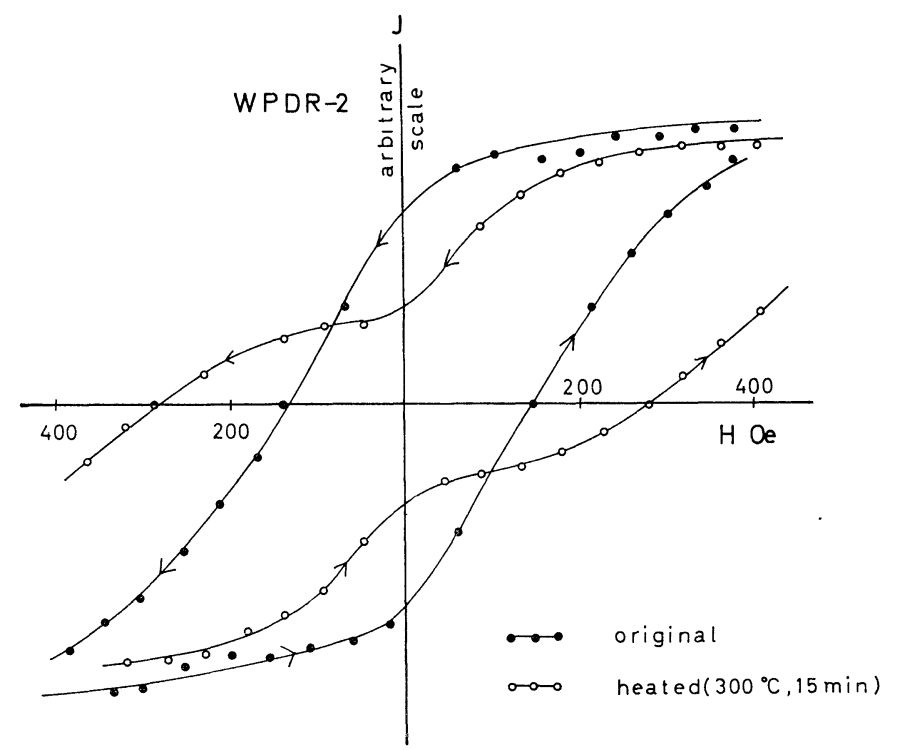

Fig. 5 Magnetization curves for original and heated sampels (heated at $300^{\circ} \mathrm{C}$ for 15 minutes). Magnetizations were measured in a field up to $2000 \mathrm{Oe}$, but only a part of the magnetization curves for a field range of $H=400 \mathrm{Oe}$ are shown. Vertical scale for the heated sample is exaggerated by a factor of five with respect to that for the original sample. 
is a result of the increasing cumulative time the sample was at $300^{\circ} \mathrm{C}$, and does not imply a dependence of reversal temperature on field. At $2600 \mathrm{Oe}$, the cumulative time was more than 150 minutes and reversal occurred close to liquid nitrogen temperature.

The reversed TRM was demagnetized by $d-c$ field and the remanent coercive force $\left(H_{c r}\right)$ was measured: the result is shown in Fig. 6-a. Compared with the $H_{c r}$ of the saturation IRM, the $H_{c r}$ of the reversed TRM is low. The TRMs were also demagnetized by an

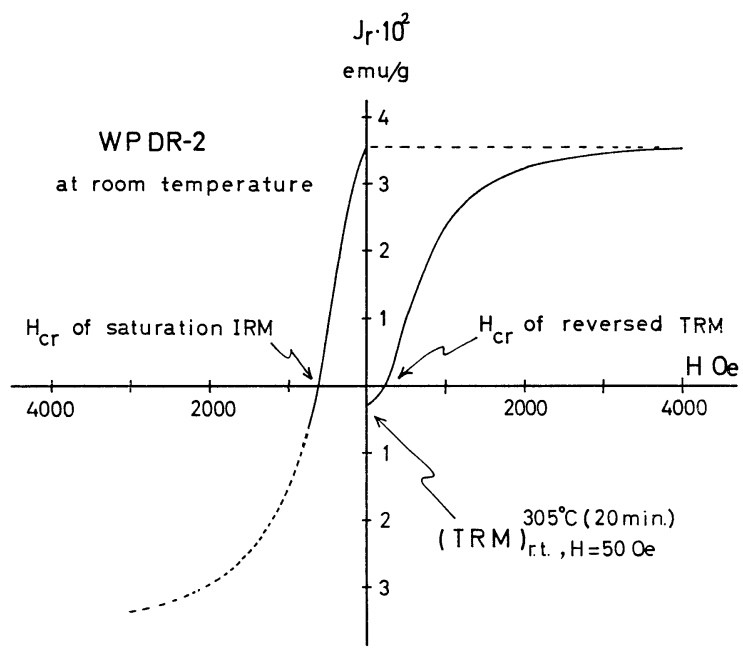

Fig. 6-a Demagnetization of reversed TRM and saturated IRM by $d$-c field. The field at which the magnetization becomes zero indicates the $H_{c r}$.

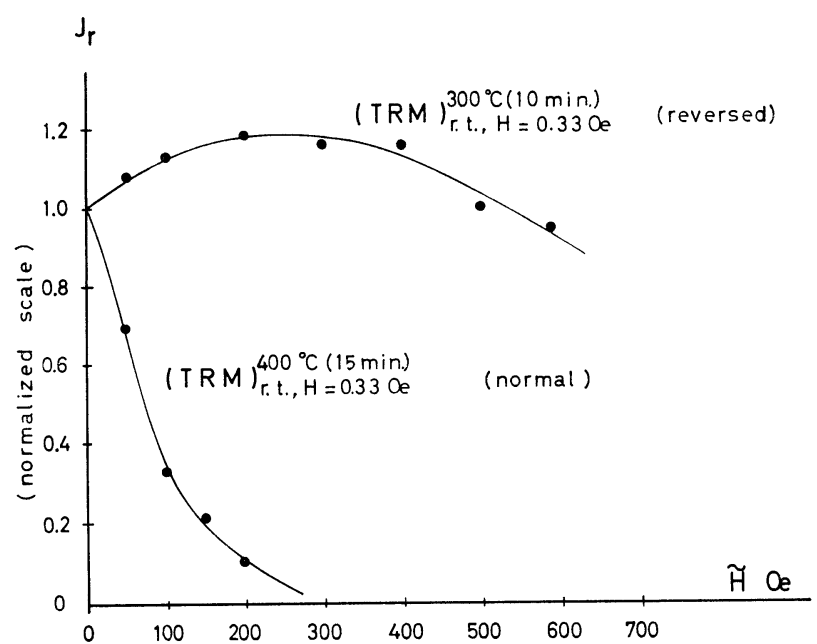

Fig. 6-b Demagnetization of TRM's by $a$ - $c$ field. The absolute

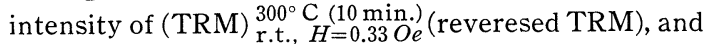
(TRM) ${ }_{\text {r.t., } H=0.33 ~}^{40 e}$ (normal TRM) at room temperature for this experiment is $4.4 \times 10^{-4}$, and $2.8 \times 10^{-3}$ $\mathrm{emu} / \mathrm{g}$, respectively. 
$a-c$ field (Fig. 6-b). From this experiment, it was shown that the reversed TRM is much harder than the normal TRM. Furthermore, the demagnetization mode of the reversed TRM is not monotonous; that is, the intensity of the reversed TRM at first increased when it was demagnetized by an $a-c$ field. This implies that the reversed TRM is composed of two antiparallel magnetizations. The normal (parallel to the field) component is easily demagnetized but the reversed component is much harder than the former. NRM was also demagnetized by an $a-c$ field, but the data are not shown in Fig. 6-b. Because the NRM was of weak intensity and relatively soft, stray fields acting during $a-c$ demagnetization produced considerable scatter in the data. However, the stability appears to be similar to that of (TRM) ${ }_{\text {r.t., }}^{400^{\circ} \mathrm{C}(15 \mathrm{~min} .)}$.

The temperature dependence of various remanent magnetizations (NRM, TRM) of WPDR-2 was measured for the temperature range from room temperature to $-196^{\circ} \mathrm{C}$. Generally, the intensity of the TRMs which are reversely magnetized increases monotonously with decrease in temperature, and that of the TRMs which are normally magnetized at room temperature (produced around $300^{\circ} \mathrm{C}$ and weak in intensity) decreases monotonously with decrease in temperature and at low-temperatures the direction reverses. The intensity of the normally magnetized TRM (produced around $400^{\circ} \mathrm{C}$ and intense) increases monotonously with decrease in temperature. Fig. 7 shows some of the results. As seen in the figure, the TRM developed from heating to $305^{\circ} \mathrm{C}$ (curves $d$ and $e$ ) becomes progressively more reversed on cooling to $-196^{\circ} \mathrm{C}$ whereas the NRM (curve a) and the TRM from heating above $305^{\circ} \mathrm{C}$ (curve $b$ and $c$ ) remain normal and change only slightly during the cooling. (2) Microscopic Observation and X-ray Analysis of WPDR-2 and Other Samples

Polished sections of all samples (original and heat-treated) were observed under a 1000power reflecting microscope. The grain sizes of opaque minerals were generally so small (less than 5 microns) that positive identification was impossible. Because of the extremely

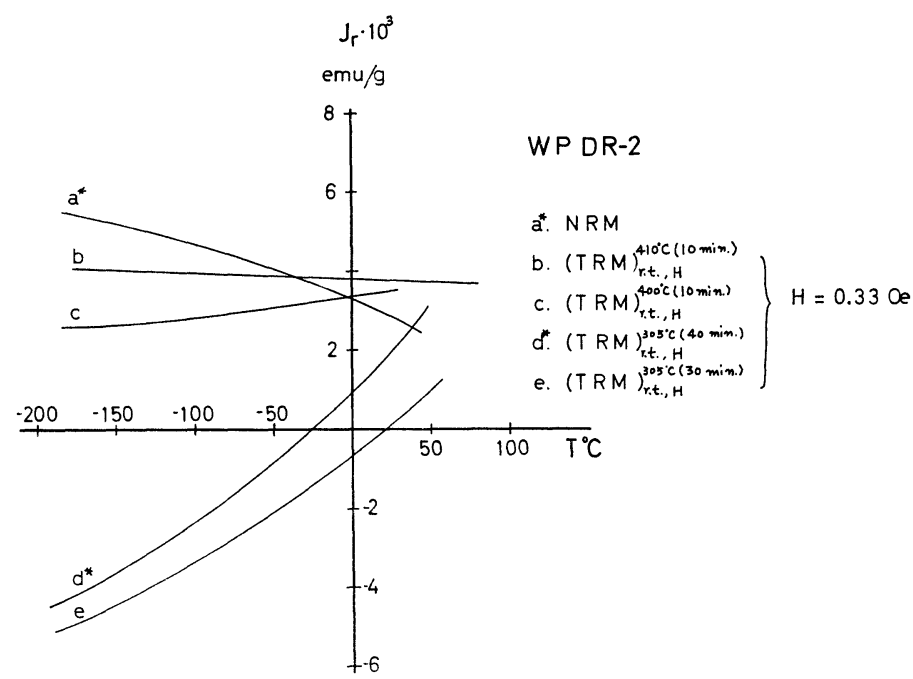

Fig. 7 Temperature dependence of TRM and NRM. Vertical scale for curves $a, d$ is exaggerated by a factor of ten. 
fine grain size, uncontaminated magnetic-mineral separates were impossible to obtain and $\mathrm{X}$-ray analysis of the concentrates was accordingly inaccurate. The results of these analyses are discussed below.

\section{Polished Section Studies}

\section{WPDR-2}

Original Abundant small grains, 5 microns and less, are present; many are elongate and skeletal. No ilmenite lamellae are observed. A few very large titanomagnetite grains exist which seem to be completely altered to titanomaghemite. A variety of types of small grains occur: some are red or yellow and are apparently hematite and/or rutile, others are dark brown and seem to be unaltered titanomagnetite.

$300^{\circ} \mathrm{C}$ The silicate background seems redder and many parts of what are probably olivine crystals seem to be altered to a fine-grained gray opaque material. The small grains generally show more yellowing and reddening to rutile and hematite, but microstructures are indeterminate.

$350^{\circ} \mathrm{C}$ Every olivine grain is rimmed by and altered to some gray opaque (possibly hematite or hematite-ilmenite). Small magnetite crystals are still abundant.

$600^{\circ} \mathrm{C}$ Grains are only slightly reddened. It is difficult to see microstructures in the small grains.

\section{WPDR-8}

Original Opaques, which are very fine grained and abundant, are present as needles and crystallites. Most are yellowish to yellow red and look like rutile and hematite. About $10 \%$ of the opaques are apparently unaltered titanomagnetite.

$270^{\circ} \mathrm{C}$ In addition to the opaques there appear large irregular opaque bodies which seem to be growing from the alteration of ground-mass material.

$300^{\circ} \mathrm{C}$ Similar to the $270^{\circ} \mathrm{C}$ samples but seemingly, more dark irregular opaque patches are present.

$600^{\circ} \mathrm{C}$ Quite red. A great deal of the opaques are now rutile and hematite, but there are still plenty of unaltered little grains. Large irregular opaque bodies seem mostly altered to rutile and hematite. Most of groundmass material is now a red and yellow mixture.

EPDR-2

Original Abundant titanomagnetite grains up to $10 \mu$ are observed which are unoxidized, i.e., no ilmenite lamellae. Cracks are apparent but no high-grade titanomaghemite is identifiable.

$300^{\circ} \mathrm{C}$ Distinct lightening in color of the opaques. Grains have begun to be mottled, apparently due to ilmenohematite(?) production.

$320^{\circ} \mathrm{C}$ Titanomagnetite is distinctly mottled-light zones appear along the (111) planes and are intimately intergrown with the host.

$350^{\circ} \mathrm{C}$ More abundant and larger streaks of lighter material (ilmenohematite?) in the titanomagnetite.

$600^{\circ} \mathrm{C}$ All titanomagnetite grains show a very fine-grained mottling of light and dark gray. Evidently a mixture of pseudobrookite and hematite. 


\section{X-ray Analysis on EPDR-2}

Original A single sharp peak at $2 \theta=35.50^{\circ}$ to $35.55^{\circ}$ (Cu target), indicating a fairly pure titanomagnetite (possibly somewhat oxidized to maghemite).

$300^{\circ} \mathrm{C}$ Main peak broadened; $2 \theta=35.35^{\circ}$ to $35.55^{\circ}$. No pseudobrookite or hematite evident. $350^{\circ} \mathrm{C}$ Similar to the $300^{\circ} \mathrm{C}$ samples.

$600^{\circ} \mathrm{C}$ Major peak broader than above. Appears that oxidation and possibly some reduction or homogenization of magnetic phases has occurred. Conspicuous lines of pseudobrookite present.

\section{Discussion}

Several physical mechanisms have so far been presented for the self-reversal of remanent magnetization. These may be classified into two categories:

i) a two-constituent model in which magnetostatic or exchange interaction plays the essential role (Néel, 1951, 1955).

ii) a one-constituent model in which the direction of $J_{s}$ reverses (Néel, 1948, 1951, 1955; Gorter and Schulkes, 1953 ; Verhoogen, 1956).

The thermomagnetic curves for WPDR-2 as shown in Fig. 4-a and 4-b are monotonous and are characteristic of Néel's Q- or R-type ferrimagnetics but not of his P-or N-types. This indicates that the self-reversal of this sample arises mainly from some magnetostatic or exchange interaction. As stated in section 2, the specimens which undergo self-reversal contain two magnetic phases with different Curie points, whereas the specimens containing a single magnetic phase do not show self-reversal of TRM in WPDR-2. We can conclude, therefore, that a magnetic interaction between two components is responsible for the production of self-reversal.

Assuming a magnetic interaction between the two components, we may schematically explain the mechanism of the self-reversal in the following way. For convenience we will call the original magnetic phase $\left(T_{c}=250^{\circ} \mathrm{C}\right)$ the "A-phase" and the second phase $\left(T_{c}=\right.$ $300^{\circ} \mathrm{C}$ ) the "B-phase". If a sample containing an intimate mixture or intergrowth of both $\mathrm{A}$ - and B-phases is cooled from $300^{\circ} \mathrm{C}$ to room temperature in an external magnetic field the B-phase will acquire a direction of magnetization parallel to the external field at and just below $300^{\circ} \mathrm{C}$. At about $250^{\circ} \mathrm{C}$ the A-phase will, under the influence of the magnetization of $\mathrm{B}$ (negative interaction), become magnetized antiparallel to the external field. The total magnetization just below $250^{\circ} \mathrm{C}$ will probably be parallel to the external field and close to zero. On further cooling, $J_{s}$ of the A-phase (antiparallel to the external field) will increase more sharply than that of the B-phase (see Fig. 4-a, 4-b) and at some temperature below $250^{\circ} \mathrm{C}$ the intensity of magnetization of the A-phase will become dominant. At that temperature self-reversal will occur.

It is evident that the nature of the total TRM depends critically on the relative abundance of the two phases and this is essentially controlled by the duration of heat-treatment. Hence, the temperature at which $J_{A}$ becomes equal to $J_{B}$, that is, the total TRM becomes zero and changes sign, depends critically on the time and the temperature of heat-treatment. 

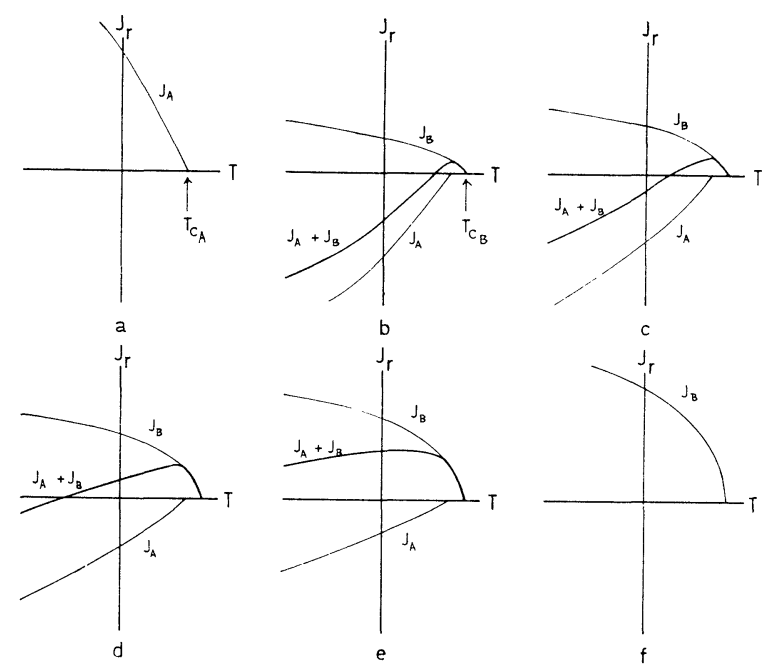

Fig. 8 Schematic explanation of various temperaturechange of TRM's. $J_{A}$ and $J_{B}$ are magnetized antiparallel and the difference of these two magnetizations are the net TRM. From $a$ to $f$, time and/or temperature of heat-treatment are increased to form a new B-phase instead of A-phase.

If the amount of A-phase, which is reversely magnetized, is small compared to that of Bphase, the reversal point will be lowered. This is explained schematically in Fig. 8. As seen, Fig. 8 explains the various temperature-dependence of TRMs (Fig. 7) on the basis of the relative amount of the A- and B-phases. For example, (TRM) ${ }_{\text {r.t., } H}^{30{ }^{\circ}} \mathrm{C}\left(30 \mathrm{~min}\right.$.) , (TRM) ${ }_{\text {r.t., } H}^{300^{\circ} \mathrm{C}(40 \mathrm{~min} \text {.) }}$,

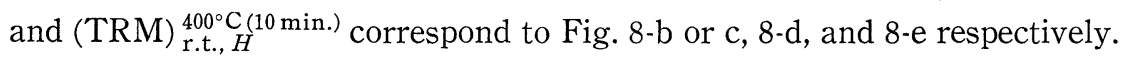

It should be pointed out that the fact that the TRM produced in 2600 Oe was normal at room temperature and did not reverse except at low temperatures is entirely a result of the time (more than 150 minutes) and temperature $\left(300^{\circ} \mathrm{C}\right)$ of heating; that is, of the relative amount of the two phases. It does not imply that a strong magnetic field depresses the reversal temperature. The magnetic coupling between phases seems to be independent of even fields as large as $2600 \mathrm{Oe}$.

The nature of the interaction may be better understood by examining the strength of the interaction field, as suggested by Uyeda (1958). If we assume a magnetostatic interaction between A- and B-phases $\left(T_{c_{A}}<T_{c_{B}}\right.$ ), the effective magnetic field acting on A around the blocking temperature of $\mathrm{A}$ is estimated to be at most about $100 \mathrm{Oe}$. As was experimentally demonstrated, even in an external field of $2600 \mathrm{Oe}$ the specimen underwent self-reversal. This is contradictory to the above estimation and seems to indicate that the assumption of a magnetostatic interaction between A- and B-phases was not valid, at least in the case of WPDR-2. The self-reversal of TRM observed in this sample must be caused by some other mechanism. As discussed by Uyeda (1958), the only mechanism capable of involving such a strong interaction field is that of exchange interaction.

As Ishikawa and Syono (1962) have shown, of the reversed TRM is produced by exchange 
interaction between two magnetic phases, the reversed TRM should have much higher coercivity than the saturation IRM. In Ishikawa and Syono's experiments, where the reversed TRM was comparable in intensity to the saturation IRM, this was demonstrated by $d$ - $c$ demagnetization, and the reversed TRM was found to have much higher $H_{c r}$ than the IRM. In our experiments the reversed TRM is of relatively low intensity and $d-c$ demagnetization does not give a true indication of coercivity, because the large IRM induced by small reverse $d$-c fields masks the TRM. For this reason, the $H_{c r}$ of the reversed TRM was found to be smaller than that of the saturation IRM (Fig. 6-a).

However, the $a-c$ demagnetization curve of the reversed TRM (Fig. 6-b) shows clearly that the true average coercivity of the TRM is much larger than $H_{c r}$, and the coercivity spectrum of reversed TRM is much harder than that of normal TRM. This is in accord with Ishikawa and Syono's findings. The small amount of increase in intensity (Fig. 6-b), however, will be explained that the small amount of A-phase which was not coupled by Bphase and consequently magnetized normally was imposed on the reversed TRM, that is,

$$
\operatorname{TRM}=\left(J_{A} \downarrow+J_{B} \uparrow\right)+J_{A} \uparrow
$$

Here, $\uparrow$ and $\downarrow$ mean parallel and antiparallel to the external field, respectively, and the bracket means that those inside the bracket are coupled with each other. The net magnetization of $\left(J_{A} \downarrow+J_{B} \uparrow\right)$ is negative. The uncoupled magnetization will vanish easily by $a-c$ demagnetization rather than the coupled magnetization.

As pointed out by Ozima and Ozima (1967), if WPDR-2 is heated above $400^{\circ} \mathrm{C}$, a third phase is produced (C-phase) which has a Curie point of about $560^{\circ} \mathrm{C}$ (see Fig. 4). The second dent observed at about $500^{\circ} \mathrm{C}$ in the $J_{r}-T$ curve (Fig. 2) may be due to a magnetic interaction between $\mathrm{B}$ - and $\mathrm{C}$-phases.

Because of the small grain size of the opaques, changes in the magnetic minerals during heating could not be adequately assesed except for sample EPDR-2. For this sample, the results of microscopic examination and $\mathrm{X}$-ray analysis indicate that the original magnetic phase (A-phase) is slightly oxidized titanomagnetite. In the sample heated at $300^{\circ} \mathrm{C}$ a newly developed phase (B-phase) is evident and presumed to be a member of the ilmenite-hematite series. The B-phase probably is the product either of oxidation of the A-phase or unmixing of a previously oxidized component, or both. Since the Curie point and the saturation magnetization of this sample indicate that the A-phase is Ti-rich titanomagnetite, it seems reasonable that the $\mathrm{B}$-phase most likely is a Ti-rich hematite. This is consistent with the result of Ishikawa and Akimoto $(1957,1958)$ that hematite with more than 50 mole percent $\mathrm{FeTiO}_{3}$ is ferrimagnetic.

The mechanism for self-reversal in the deep-sea basalts is not like that in the Haruna dacite. Uyeda (1958) found that the Haruna reversal is associated with the presence of an ilmenohematite-with a composition about 50 mole percent $\mathrm{FeTiO}_{3} \cdot 50$ mole percent $\mathrm{Fe}_{2} \mathrm{O}_{3}$ but it occurred when that phase alone was present. Moreover, there is a difference in Curie temperature between the B-phase of the oceanic sample $\left(300^{\circ} \mathrm{C}\right)$ and that of the Haruna dacite $\left(250^{\circ} \mathrm{C}\right)$, indicating a difference in composition. In the deep-sea basalts, when only 
the B-phase (or C-phase) was present, the sample failed to show self-reversal. Harard and Lewis (1965) concluded that the self-reversal of TRM in some Indian basalts was the result of interaction of two phases, one (titanomaghemite) an oxidation product of the other (titanomagnetite). However, they could not verify the existence of the B-phase microscopically.

As shown in Figure 1, samples WPDR-8 and EPDR-2 show a TRM-production mode and self-reversal phenomenon similar to those of WPDR-2; they also show an irreversible change in saturation magnetization during heating, in air or in vacuo (Ozima et al, 1968) like that of WPDR-2. These facts strongly suggest that the mechanisms of self-reversal of TRM in these two samples is essentially the same as that in WPDR-2.

The fineness of grain size and abundance of volcanic glass indicate that the oceanic basalts have chilled quickly, probably being quenched by ocean water after eruption on the sea foor. It is suspected that this mode of emplacement is the basic cause for the discrepancy between the magnetic behaviour of oceanic and continental eruptives.

Rapid chilling reduces the opportunity for high-temperature oxidation (development of ilmenite lamellae, metailmenite, and pseudobrookite) which is so common in continental lavas. Quenching of the lava also promotes the formation of large proportions of volcanic glass in which ionic iron can be concentrated and possibly enhances the amount of disorder in the crystal structure of any titanomagnetite crystals. In the water-rich environment, the small titanomagnetite crystals can be affected by low-temperature single-phase oxidation, that is, alteration to titanomaghemite. Since the dissolved-oxygen content of the oceanic water throughout the ocean basins is not greatly different, the principal factor in the degree of single-phase oxidation is duration of exposure. It is noteworthy that the three samples which possess the lowest Curie temperature (indicating the least amount of oxidation) all showed self-reversal of TRM and are the youngest of the dredge samples-all less than 26 million years old (see Ozima et al, 1968).

Apparently, on heating to $300^{\circ} \mathrm{C}$, some portions (either initially oxidized or oxidized during the experiment) of the less-altered magnetic grains unmix to form a second ferrimagnetic phase, presumably ilmenohematite, which thereby enables the acquisition of selfreversed TRM. Temperatures near $600^{\circ} \mathrm{C}$ permit oxidation of titanomagnetite components to titanomaghemite, ordering of the internal structure in titanomaghemite already present, and devitrification and breakdown of the Fe-rich glass to various silicates and magnetite. This results in greatly increased Curie temperature and saturation magnetization (as discussed by Ozima et al, 1968).

\section{Conclusion}

From the results of magnetic experiments, X-ray analysis, and microscopic observations, we conclude that the reversed TRM's observed during heating in some submarine basalts are most probably due to an exchange interaction between two magnetic phases. The A-phase is originally present slightly oxidized Ti-rich titanomagnetite and the B-phase is ilmenohematite which forms from the oxidation of the A-phase during heating. The 
original magnetic phase gradually changes to the other phase when it is heated in air and when it has disappeared, the sample no longer shows self-reversal.

Although the magnetic properties of dredged basalts are not well known, the high percentage of self-reversed samples in this study, particularly for rocks less than 30 m.y. old, would imply that a large proportion of the relatively young oceanic rocks could be expected to behave similarly.

\section{Acknowledgement}

We are grateful to Professor V. Vacquier of Scripps Institution of Oceanography who generously provided dredged basalts for our study. We thanks Drs. Minoru Ozima and D. Dunlop for helpful discussions and critical reading of this manuscript.

\section{References}

Akimoto, S., and M. Yama-ai, unpublished paper presented at semi-annual meeting of the Society of Terrestrial Magnetism and Electricity, Japan, 1960.

Bhimasankaram, V.L.S., Partial magnetic self-reversal of pyrrhotite, Nature, 202, 478-480, 1964.

Carmichael, C.M., The magnetic properties of ilmenite-hematite crystals, Proc. Roy. Soc., A 263, 508530, 1961.

Carmichael, R.S., and M.D. Fuller, Effect of plastic deformation on magnetic properties of nickel and interpretation of an early self-reversal of magnetization observed by Nagaoka, J. Geomag. Geoelectr., 19, 181-193, 1967.

Everitt, C.W.F., Self-reversal of magnetization in a shale containing pyrrhotite, Phil. Mag., 7, 831-842, 1962.

Gorter, E.W., and J.A. Schulkes, Reversal of spontaneous magnetization as a function of temperature in LiFeCr spinels, Phys. Rev., 90, 487-488, 1953.

Havard, A.D., and M. Lewis, Reversed partial thermo-magnetic remanence in natural and synthetic titano-magnetites, Geophys. J., 10, 59-68, 1965.

Ishikawa, Y., and Y. Syono, Reverse thermo-remanent magnetism in the $\mathrm{FeTiO}_{3}-\mathrm{Fe}_{3} \mathrm{O}_{3}$ system, $J$. Phys. Soc. Japan, 17, Suppl. B-I 714-718, 1962.

Ishikawa, Y., and $\mathrm{S}$. Akimoto, Magnetic properties of the $\mathrm{FeTiO}_{3}-\mathrm{Fe}_{2} \mathrm{O}_{3}$ solid solution series, J. Phys. Soc. Japan, 12, 1083-1098, 1957.

Ishikawa, Y., and S. Akimoto, Magnetic property and crystal chemistry of ilmenite $\left(\mathrm{MeTiO}_{3}\right)$ and hematite $\left(\alpha \mathrm{Fe}_{2} \mathrm{O}_{3}\right)$ system, II Magnetic property, J. Phys. Soc. Japan, 13, 1298-1310, 1958.

Kalashnikov, A.G., S. Yu. Brodskaya, and V.A. Zhilyeeva, Paleomagnetic studies in USSR, Izv. Akad. Naku. SSSR, Geophys. Seri. No. 8, 1189-1191, 1961.

Kobayashi, K., and M.D. Fuller, Stable remanence and memory phenomenon in multi-domain materials with special reference to magnetite, Sci. Rep. No. 5, Dept. Earth Planet. Sci., Univ. of Pittsburgh, 1967.

Meitzner, W., Der Einfluss von Entmischung und Oxydation auf die magnetischen Eigenschaften der Titanomagnetit in Basalten, bei 250 und $350^{\circ} \mathrm{C}$, Beiträge Mineralogie und Petrographie, 9, 320-352, 1963.

Nagaoka, H., Combined effects of torsion and longitudinal stress on the magnetization of nickel, $J$. College of Science (Tokyo Imperial Univ.), 2, 283-303, 1888.

Nagata, T., S. Akimoto, and S. Uyeda, Reverse thermo-remanent magnetism, Proc. Japan Acad., 27, 643-645, 1951.

Néel, L., Propriétés magnétiques des ferrites; Ferrimagnétisme et antiferromagnétisme, Ann. Physiq., 
3, 137-198, 1948.

Néel, L., L’inversion de l'aimantation permanente des roches, Ann. Géophysiq., 7, 90-102, 1951.

Néel, L., Some theoretical aspects of rock-magnetism, Adv. Phys., 4, 191-243, 1955.

Ozima, M., The acquisition mechanism of a remanent magnetization with particular reference to inverse thermo-remanent magnetization, Thesis, Univ. of Tokyo, 1963.

Ozima, M., M. Ozima, and S. Akimoto, Low temperature characteristics of remanent magnetization of magnetite-self-reversal and recovery phenomenon of remanent magnetization, J. Geomag. Geoelectr., 16, 165-177, 1964.

Ozima, M., and M. Ozima, Self-reversal of remanent magnetization in some dredged submarine basalts, Earth Planet. Sci. Letters, 3, 213-215, 1967.

Ozima, M., M. Ozima, and I. Kaneoka, K-Ar ages and magnetic properties of some dredged submarine basalts and their geophysical implications, J. Geophys. Res., 73, 711-723, 1968.

Sakamoto, N., Magnetic properties of Cobalt Titanate, J. Phys. Soc. Japan, 17, 99-102, 1962.

Schult, A., Über die Umkehr der remanenten Magnetisierung von Titanomagnetiten in Basalten, Beiträge zur Mineralogie und Petrographie, 11, 196-216, 1965.

Smith, S.W.J., A.A. Dee, and W.V. Mayneord, Magnetism of annealed carbon steels, Proc. Phys. Soc. (London), 37, 1-14, 1924.

Smith, S.W.J., and J. Guild, Self-demagnetization of annealed steel rods, Proc. Phys. Soc. (London), 24, 344-349, 1912.

Uyeda, S., Thermo-remanent magnetism as a medium of paleomagnetism with special reference to reverse thermo-remanent magnetism, Jap. J. Geophys., 2, 1-123, 1958.

Verhoogen, J., Ionic ordering and self-reversal of magnetization in impure magnetites, J. Geophys. Res., 61, 201-209, 1956.

Vlasov, A. Ya, A.G. Zvegintsef, and V.F. Pavlov, Self-reversal of the magnetization of synthetic sediments, Izr. Geophys. Ser., 4, 556-561, 1964.

Yama-ai, M., M. Ozima, and T. Nagata, Self-reversal of remanent magnetization of magnetite at low temperatures, Nature, 198, 4886, 1963. 